\title{
Determining the age and growth of wild octopus using stylet increment analysis
}

\author{
Stephen C. Leporati*, Jayson M. Semmens, Gretta T. Pecl \\ Tasmanian Aquaculture and Fisheries Institute Marine Research Laboratories, University of Tasmanian, Private Bag 49, \\ Hobart, Tasmania 7001, Australia
}

\begin{abstract}
Stylet increment analysis is a method of octopus age estimation that quantifies growth rings within stylets (reduced internal shells found in the mantle). This method was applied to wild Octopus pallidus to determine gender and seasonal influences on age and growth. A total of 503 individuals (94 males and 409 females) were aged, revealing that $O$. pallidus can reach a maximum age of approximately $1.6 \mathrm{yr}$ and that spawning occurs throughout the year. Male octopuses on average were significantly larger (550 and $482 \mathrm{~g}$ for males and females, respectively) and older (259 and $243 \mathrm{~d}$ for males and females, respectively) than female, and overall growth rates were positively correlated with temperature at hatching. However, these differences were secondary to individual growth heterogeneity. Growth of males ranged from 1.32 to $5.33 \%$ body weight (bw) d $\mathrm{d}^{-1}$ and females from 1.55 to $6.9 \%$ bw d $\mathrm{d}^{-1}$, with no relationship between age and size evident regardless of sex. Stylet increment analysis is a promising technique that could play a role similar role to statoliths in squid as an ageing tool.
\end{abstract}

KEY WORDS: Octopus $\cdot$ Stylet increment analysis $\cdot$ Age $\cdot$ Growth $\cdot$ Seasonal effects

\section{INTRODUCTION}

Over the past 2 decades global octopus catches have increased by approximately $100000 \mathrm{t}$, with more than $350000 \mathrm{t}$ caught in 2005, predominately from Asia (218977 t), Africa (65 $743 \mathrm{t}$ ) and Europe (44 $800 \mathrm{t}$ ) (FAO 2005). The extent to which octopus stocks can withstand this escalating pressure is largely unknown. Of paramount importance is the need for an accurate, reliable, cost effective and easy to use method of octopus age estimation (Semmens et al. 2004). Without accurate age estimation, studies on octopus growth, recruitment, productivity and population structure rely on assumptions derived from morphological assessments and catch data (Jackson et al. 1997, Campana 2001). A commonly applied method that uses mantle length as the defining measure of octopus growth is modal progression analysis (MPA). MPA relies on the assumption that age is closely related to size (Challier et al. 2002); however, cephalopod growth in general is extremely variable (Forsythe \& Van Heukelem 1987, Semmens et al. 2004), rendering this assumption incongruous
(Mangold \& von Boletzky 1973, Jackson et al. 2000). Lack of a strong age/size relationship combined with the generally short life span $(<2 \mathrm{yr})$ of most octopus species (Boyle \& Rodhouse 2005), prevents the practical application of cohort analysis without intensive sampling (Cortez et al. 1999). This reliance on techniques that can produce inaccurate growth rates and longevities by not accounting for growth plasticity creates uncertainty in management decisions potentially jeopardising the sustainability of stocks (Jackson 1994, Boyle \& von Boletzky 1996).

To date, 4 main approaches to octopus age estimation have been applied to a range of species with variable levels of success. (1) Beak microstructure increment analysis, which investigates the formation of growth rings in the beak (Raya \& Hernández-García 1998, Hernández-López \& Castro-Hernández 2001, Oosthuizen 2003); (2) laboratory growth studies that investigate temperature effects, diets and metabolic rates (Forsythe 1984, Forsythe \& Hanlon 1988, Segawa \& Nomoto 2002, Iglesias et al. 2004, Miliou et al. 2005); (3) tag-recapture studies that look at the growth of 
octopuses for a specific period of time (Domain et al. 2000); and (4) histological quantification of lipofuscin in nervous tissue, which is proportional to physiological age and is used as a proxy for chronological age (Sobrino \& Real 2003). All 4 of these methods have intrinsic limitations: (1) beak microstructure increment analysis is affected by processes such as feeding that wear down the beak, resulting in inaccurate estimates (Hernández-López \& Castro-Hernández 2001); (2) laboratory derived findings are not guaranteed to be transferable to wild populations (Joll 1977, Pecl \& Moltschaniwskyj 1999); (3) factors such as tagging mortality, growth reduction due to stress, inability to predict age before the tag date, reliance on consistent recaptures and accurate reporting must all be considered when conducting a tag-recapture study (Semmens et al. 2007); and (4) histological quantification of lipofuscin is yet to be validated in animals of known age (Semmens et al. 2004). What is required is an accurate and validated method of age determination that uses similar internal structures to those found in teleost fish (otoliths and vertebrae), which does not rely on external features such as beaks and morphometric measurements, avoids the uncertainty of laboratory studies and is not as limited in scope as tagging studies.

Two types of hard internal structures are present in octopuses: (1) statoliths (analogous to otoliths), which are small paired calcareous structures associated with sensory epithelia, found in the cranium (Lombarte et al. 2006) and (2) stylets, which are paired elongate structures, also referred to as vestigial shells, found in the mantle musculature near the base of the gills (Bizikov 2004, Doubleday et al. 2006). Successful age estimates have been achieved for many squid (Jackson 1994) and some cuttlefish (Bettencourt \& Guerra 2001, Challier et al. 2002) species by counting validated concentric daily increments (growth rings) found in statoliths (Boyle \& Rodhouse 2005). However, this technique has failed to provide results for octopus due to a lack of growth rings and the morphology of octopus statoliths not possessing the same landmarks as those of squid and cuttlefish, which minimises increment visualisation (Lombarte et al. 2006). Stylets, however, do have concentric rings (Bizikov 2004) and have been validated for age estimation by Doubleday et al. (2006) using Octopus pallidus of known age reared in captivity. This method of stylet increment analysis showed that increments in O. pallidus are deposited daily and provide results similar in reliability and accuracy to statoliths in squid, and otoliths and vertebrae in teleost fishes.

The present study applied the same ageing techniques as Doubleday et al. (2006) on a wild population of the same species, Octopus pallidus. This octopus is a semelparous (authors' unpubl. data), benthic species of medium size (maximum weight, $1.2 \mathrm{~kg}$ ), endemic to southeast Australian waters at depths from 7 to $275 \mathrm{~m}$ (Stranks 1988) and is the target of a rapidly expanding commercial fishery (Ziegler et al. 2007). The broad aim of this study was to determine the age and growth of Octopus pallidus, with the specific objectives of (1) providing maximum age estimates, (2) investigating sex-specific growth and (3) quantifying age and growth on a seasonal basis. This is the first study to estimate the age and growth of wild octopus using validated stylet increment analysis.

\section{MATERIALS AND METHODS}

Specimen collection. Samples were collected every second month during April 2005 to November 2006 (10 independent trips) from Bass Strait waters off northwestern Tasmania, Australia. A dedicated unbaited bottom-set long line approximately $1000 \mathrm{~m}$ in length (from $40^{\circ} 43.342^{\prime} \mathrm{S}, 145^{\circ} 20.060^{\prime} \mathrm{E}$ [west end] to $40^{\circ} 43.788^{\prime} \mathrm{S}, 145^{\circ} 20.505^{\prime} \mathrm{E}$ [east end]) at a depth of $26 \mathrm{~m}$, first set on 15 February 2005, was used to collect specimens. Modelled on commercial fishery long lines, this research line was hauled less frequently (approximately every $65 \mathrm{~d}$ compared with commercial lines hauled approximately every $20 \mathrm{~d}$ ) and only for research sampling. The research line was set at the one location using a Global Positioning System (GPS) receiver. The research line consisted of research pots of variable volumes: $124 \mathrm{ml}(\mathrm{n}=15), 493 \mathrm{ml}(\mathrm{n}=15)$, $927 \mathrm{ml}(\mathrm{n}=15)$, all made from PVC pipe, and $3000 \mathrm{ml}$ ( $n=100)$ commercial fishery pots made from moulded plastic. Different pot sizes were used so a variety of octopus size ranges could be obtained based on the premise that pot volume correlates with octopus size (Iribarne 1990, Katsanevakis \& Verriopoulos 2004). However, the different pot sizes failed to provide a range of octopus sizes, with all pot types catching similar sized octopuses with no difference in fishing success. As such, when research pots were lost or damaged, they were replaced with commercial pots. A general ratio of approximately 5 commercial pots for every research pot was maintained throughout the sampling period.

After landing, morphological measurements were taken and dissections performed on fresh specimens. The octopuses were weighed and measured to the nearest $0.1 \mathrm{~g}$ and $1 \mathrm{~mm}$, respectively, and measurements were taken of dorsal mantle length, ventral mantle length and head width. A total of 113 males and 536 females were caught, of which $109(96 \%)$ of the males and $485(90 \%)$ of the females were processed for ageing analysis. 
Stylet preparation. The ageing techniques used in this study are based on the work of Doubleday et al. (2006) who validated, using known-age Octopus pallidus reared in captivity, that each concentric ring from the nucleus to the outer edge of the stylet is equal to $1 \mathrm{~d}$. Stylets are located within the mantle musculature at the base of the gills where the posterodorsal mantle abductor muscles are attached to the mantle (Fig. 1) (Bizikov 2004). To extract the stylets, incisions at the anchorage points of the abductor muscles were made and then fine forceps were used for removal. The paired stylets were then preserved in $70 \%$ ethanol. The stylet in the best condition (i.e. complete structure with minimal damage) was chosen for increment analysis; if both stylets were of similar condition one was chosen randomly. The stylets were weighed to the nearest $0.001 \mathrm{~g}$ and the rostral and posterior lengths and width of the stylet at the elbow (Doubleday et al. 2006) were measured to the nearest $0.001 \mathrm{~mm}$. A subsample of 20 individuals from one trip had one stylet preserved in $70 \%$ ethanol and another preserved in $4 \%$ formalin for comparisons between preservation techniques.

A transverse section was cut from the region immediately after the elbow on the posterior side of the stylet. The section was positioned on a glass microscope slide and surrounded by thermoplastic cement (Crystal Bond ${ }^{\mathrm{TM}}$ 509). The slide was then placed on a hotplate $\left(\sim 130^{\circ} \mathrm{C}\right)$ until the crystal bond was viscous enough to be moulded with a steel probe yet not hot enough to run. After the crystal bond set ( 1 $\mathrm{min}$ ) the slide was ground on damp $1200 \mu \mathrm{m}$ sandpaper and progressively polished on 12,9 and $5 \mu \mathrm{m}$ damp lapping film to a thickness of $\sim 0.5 \mathrm{~mm}$. A final polish on a pellon PSU PA-K polishing disk (Kemet Australia Pty) impregnated with an alumina powder $(0.05 \mu \mathrm{m})$ and water slurry was performed to remove surface scratches. The section was then viewed under a com- pound microscope (Nikon Eclipse E400) connected to a video camera (Leica DC300F) and computer using Leica IM50 (version 1.20) software. At 400× magnification, $\sim 5$ to 10 images were taken per section depending on clarity of the image and width of the section. Images were taken sequentially from the nucleus to the outer edge following the clearest line of concentric rings. The process of polishing, viewing the stylet and capturing the images needed to be completed within $5 \mathrm{~min}$, as beyond this time the section can dry out and become unreadable (as per Doubleday et al. 2006). Once saved to a computer, the digital images were stitched together using Adobe Photoshop to create a composite plane of the section. The concentric rings were then counted using a hand counter from the nucleus to the outer edge (Fig. 2). Two non-consecutive counts were made for each section and a third performed if the difference between the counts was $>10 \%$ of the mean. If the closest 2 counts (of the 3) were $>10 \%$ of the mean, then the stylet was excluded from future analysis. If the rings were obscured in a small area, the lateral distance was measured and then transposed to an equivalent readable area and extrapolated. Stylets were excluded from the analysis if the number of rings extrapolated was $>20 \%$ of the total count.

Data analysis. Instantaneous growth rate $(G)$ was calculated using the following equation:

$$
G=\frac{\ln \left(W t_{2}\right)-\ln \left(W t_{1}\right)}{\Delta t}
$$

where $W t_{1}$ and $W t_{2}$ are the individual weights $(W)$ at times $t_{1}$ (hatch) and $t_{2}$ (capture), and $\Delta t$ is the time interval in days between 2 periods (age) (Forsythe \& Van Heukelem 1987). An estimated size at hatching of $0.25 \mathrm{~g}$ derived from a laboratory study on Octopus pallidus growth was used (Leporati et al. 2007).

A chi-squared test $\left(\chi^{2}\right)$ was used to examine difference in sex ratios between haul seasons. A $t$-test was performed to determine whether there were any differences in age estimates and total weight between males and females, and age estimations between the ethanol and formalin treated stylets. Weight at age was calculated by adjusting mean weight for each haul season in accordance with overall mean age for both males and females. Analyses of covariance (ANCOVA) were performed to determine any significant differences in weight at age between sexes, and haul seasons for both sexes. Analyses of variance were performed to determine whether there were any significant differences in growth (\% body weight $[\mathrm{bw}] \mathrm{d}^{-1}$ ) between 


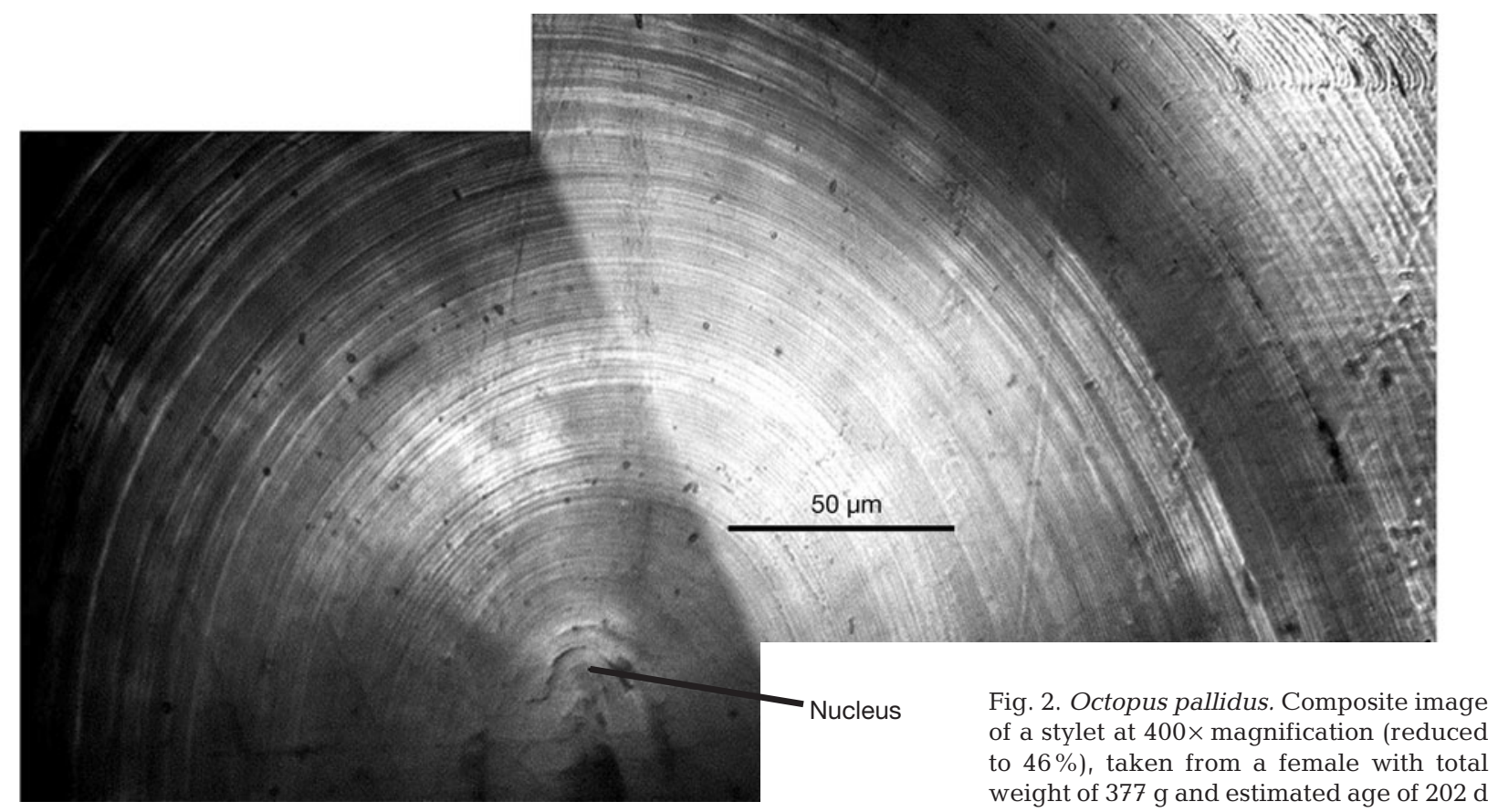

sexes, and hatch seasons for both sexes. A post hoc test (Tukey's B test) was performed to determine the extent of differences in growth between female hatch seasons. All data were $\log _{10}$ transformed before analysis to ensure a normal distribution.

Hatch dates were estimated by back-calculating age data from the haul date of each individual. Individuals were then grouped into hatch seasons and aligned with satellite-derived estimates of sea surface temperature data obtained from the Commonwealth Scientific Industrial Research Organisation (CSIRO). This was performed to determine the effects of seasonal temperatures at hatching on the overall growth of each individual. Seasons were defined as austral summer (December to February), autumn (March to May), winter (June to August) and spring (September to November).

\section{RESULTS}

The formalin and ethanol treated stylets did not show any significant differences in age estimation $(t=$ -0.283 , df $=14, p=0.782$ ), indicating that either method of treatment was applicable. However, the outer sheath of the formalin treated stylets tended to swell, making them weaker and more susceptible to damage and, hence, ethanol treated stylets were used throughout the study.

Sex ratios were significantly different between haul seasons $\left(\chi^{2}=363.849, \mathrm{df}=12, \mathrm{p}=0.000\right)$ and generally dominated by females, ranging from 76 to $89 \%$ (mean $\pm \mathrm{SE}=82.6 \pm 2.35 \%)$ compared with males, which ranged from 14 to $24 \%$ (mean $=17.3 \pm 1.54 \%$ ) (Table 1$)$. A total of 94 males and 409 females were successfully

Table 1. Octopus pallidus. Summary of research line catch and composition

\begin{tabular}{|c|c|c|c|c|c|c|c|c|c|c|}
\hline \multirow[t]{2}{*}{ Trip } & \multirow[t]{2}{*}{ Haul season } & \multirow{2}{*}{$\begin{array}{l}\text { No. of } \\
\text { pots }\end{array}$} & \multicolumn{4}{|c|}{$\longrightarrow$ Male octopus - } & \multirow[b]{2}{*}{$\mathrm{n}$} & \multicolumn{2}{|c|}{ Female octopus - } & \multirow[b]{2}{*}{$\mathrm{SE}$} \\
\hline & & & $\mathrm{n}$ & $\begin{array}{l}\text { Weight } \\
\text { range }(g)\end{array}$ & $\begin{array}{c}\text { Mean } \\
\text { weight }(g)\end{array}$ & $\mathrm{SE}$ & & $\begin{array}{l}\text { Weight } \\
\text { range }(g)\end{array}$ & $\begin{array}{c}\text { Mean } \\
\text { weight }(g)\end{array}$ & \\
\hline 1 & Autumn 2005 & 100 & 12 & $516-963$ & 672 & 15.9 & 62 & $386-796$ & 549 & 16.2 \\
\hline 2 & Winter 2005 & 177 & 34 & $476-789$ & 647 & 14.3 & 92 & $349-749$ & 531 & 16.3 \\
\hline 3 & Winter 2005 & 130 & 12 & $420-1003$ & 536 & 12.2 & 51 & $318-674$ & 501 & 16.9 \\
\hline 4 & Spring 2005 & 176 & 18 & 401-793 & 494 & 12.8 & 81 & $335-981$ & 526 & 15.2 \\
\hline 5 & Summer 2005/06 & 160 & 10 & $345-595$ & 456 & 9.7 & 88 & $275-686$ & 479 & 13.0 \\
\hline 6 & Summer 2005/06 & 160 & 8 & $338-635$ & 477 & 10.5 & 61 & $295-646$ & 469 & 15.1 \\
\hline 7 & Autumn 2006 & 149 & 21 & $417-599$ & 511 & 10.8 & 99 & $298-661$ & 437 & 10.8 \\
\hline 8 & Winter 2006 & 116 & 18 & $400-620$ & 501 & 10.2 & 60 & $322-635$ & 460 & 11.2 \\
\hline 9 & Spring 2006 & 139 & 9 & $360-581$ & 448 & 13.2 & 45 & $293-658$ & 468 & 13.1 \\
\hline 10 & Spring 2006 & 110 & 10 & $245-674$ & 478 & 11.3 & 52 & $320-646$ & 446 & 11.2 \\
\hline
\end{tabular}




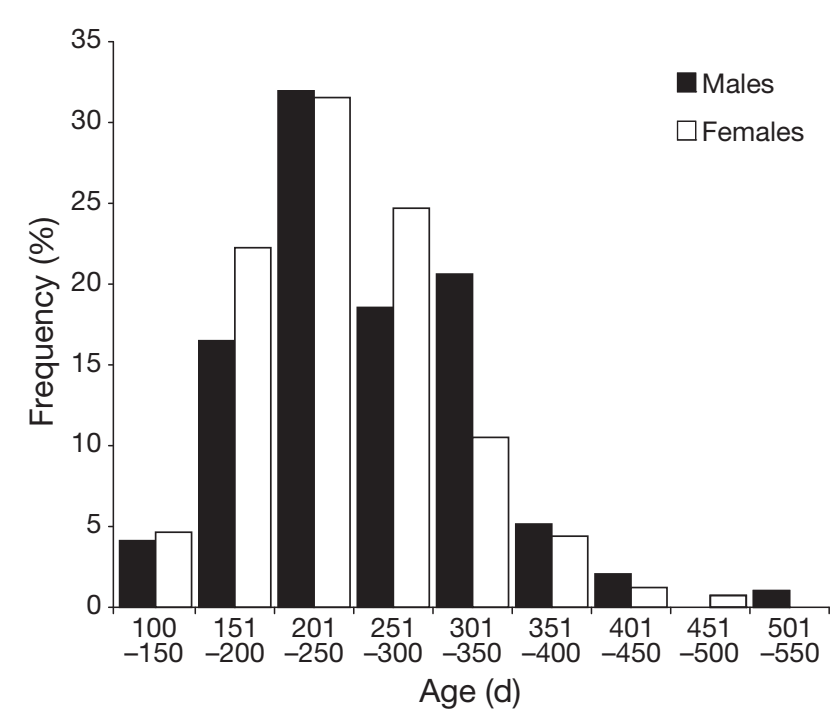

Fig. 3. Octopus pallidus. Age frequency distribution of males and females for all haul seasons

aged; the males ranged in age from 142 to $589 \mathrm{~d}$ (mean $\pm \mathrm{SE}=259 \pm 7.623 \mathrm{~d}$ ) and in total weight from 245 to $1003 \mathrm{~g}$ (mean $=550 \pm 11.73 \mathrm{~g})$, whereas the females ranged in age from 110 to $475 \mathrm{~d}$ (mean $=243 \pm 3.182 \mathrm{~d}$ ) and in total weight from 276 to $981 \mathrm{~g}$ (mean $=485 \pm$ $4.606 \mathrm{~g})$ (Fig. 3). Males were significantly larger $(t=$ 2.461, df $=97, \mathrm{p}=0.016)$ and older $(t=3.348, \mathrm{df}=97$, $\mathrm{p}=0.001$ ) than the females. Brooding females with eggs laid in the pots were observed on each trip. ANCOVA revealed there were no significant differences between males and females in weight at age ( $F=$ 1.212, df $=314, \mathrm{p}=0.067$ ), and no significant differences in weight at age between haul seasons for males $(F=0.322, \mathrm{df}=6, \mathrm{p}=0.924)$ or females $(F=1.239, \mathrm{df}=$ $6, \mathrm{p}=0.285)$; however, there was a general trend of progressively declining weight at age over haul seasons (Fig. 4).

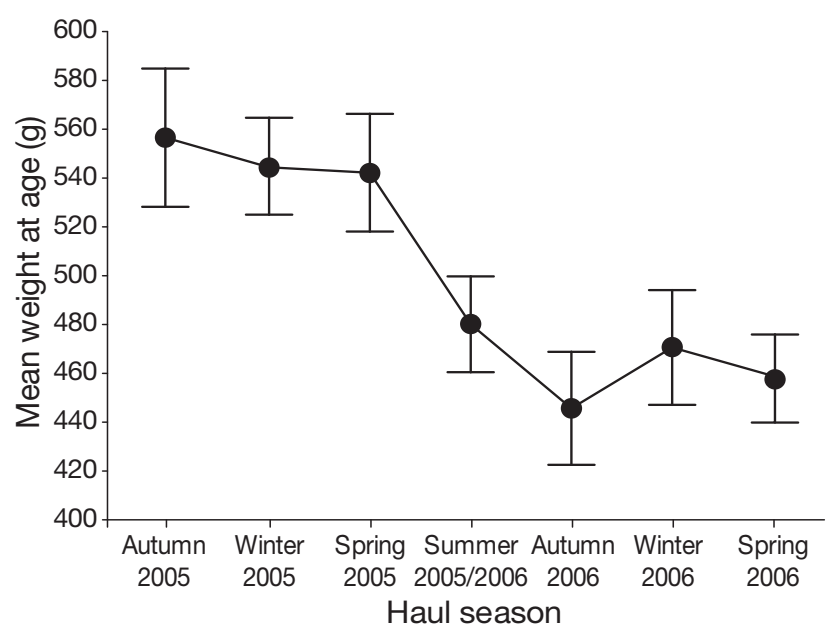

Fig. 4. Octopus pallidus. Mean $( \pm \mathrm{SE})$ weight at age for males and females combined during each haul season
There was no correlation between age and total weight for either males $\left(r^{2}=0.0338\right)$ (Fig. 5) or females $\left(r^{2}=0.0009\right)$ (Fig. 5). Also, no correlations were evident when age was compared with all other morphological measurements in males and females. Stylet length (male: $r^{2}=0.066$, female: $r^{2}=0.120$ ), width (male: $r^{2}=0.026$, female: $r^{2}=0.068$ ) and weight (male: $r^{2}=$ 0.086 , female: $r^{2}=0.189$ ) were also unrelated to octopus body weight for both sexes.

Instantaneous growth rates $\left(G\right.$ as $\% b^{-1}$ ) were not significantly different between males and females $(F=$ 2.572 , df $=2, \mathrm{p}=0.077)$; males ranged from 1.32 to $5.33 \% \mathrm{bw} \mathrm{d}^{-1}$ (mean $\pm \mathrm{SE}=3.21 \pm 0.09 \%$ ) and females from 1.55 to $6.9 \% \mathrm{bw} \mathrm{d}^{-1}$ (mean $=3.31 \pm 0.045 \%$ ). Although males showed no significant differences in growth between hatch seasons $(F=2.055$, df $=7, \mathrm{p}=$ $0.57)$ females $\operatorname{did}(F=3.261, \mathrm{df}=7, \mathrm{p}=0.002)$. A post hoc test on female growth revealed that females from winter 2004 and spring 2005 hatch seasons had the lowest mean growth rates and that females from autumn 2006 had the highest mean growth for any hatch season (Fig. 6).

Back-calculated hatch dates indicated that spawning occurred throughout the year. Insufficient numbers of males (mean = 14 ind. per haul season) minimised the identification of hatch and haul season trends; however, some general trends were evident and require further sampling for clarification. Males caught during autumn 2005 and 2006 haul seasons predominantly hatched during the spring $(\mathrm{Sp})$ of the preceding year $(2005=50 \%$ [Sp], $2006=45 \%[\mathrm{Sp}])$. Males caught during the winter 2005 and 2006 haul seasons predominantly hatched during the spring and/or summer $(\mathrm{Su})$ of the preceding year $\left(2005=38 \%[\mathrm{Sp}], 38 \%[\mathrm{Su}]_{\text {; }}\right.$ $2006=81 \%$ [Sp]). Males caught during the spring 2005 and 2006 haul seasons predominantly hatched during the summer of the preceding year $(2005=55 \%$ [Su], $2006=73 \%$ [Su]). For the single summer haul season sample in 2005/06, the majority of individuals hatched during the winter (Wi) of the preceding year $(2005 / 06=$ $45 \%$ [Wi]). The higher numbers of females in each haul season (mean $=58$ individuals) allowed for greater confidence in trends between hatch and haul seasons. Females caught during the autumn 2005 and 2006 haul seasons predominantly hatched during the winter and/or early spring of the preceding year $(2005=45 \%$ [Wi], $37 \%$ [Sp]; $2006=55 \%$ [Wi], 26\% [Sp]). The majority of the females caught during the winter 2005 and 2006 haul seasons hatched during the late spring and/or summer of the preceding year $(2005=67 \%$ [Su], $21 \%$ [Sp]; $2006=51 \%$ [Su], $34 \%$ [Sp]). Females caught during spring 2005 and 2006 haul seasons predominantly hatched during the summer and/or autumn $(\mathrm{Au})$ of the preceding year $(2005=45 \%$ [Su], $49 \%[\mathrm{Au}] ; 2006=39 \%$ [Su], $37 \%$ [Au]). For the single 


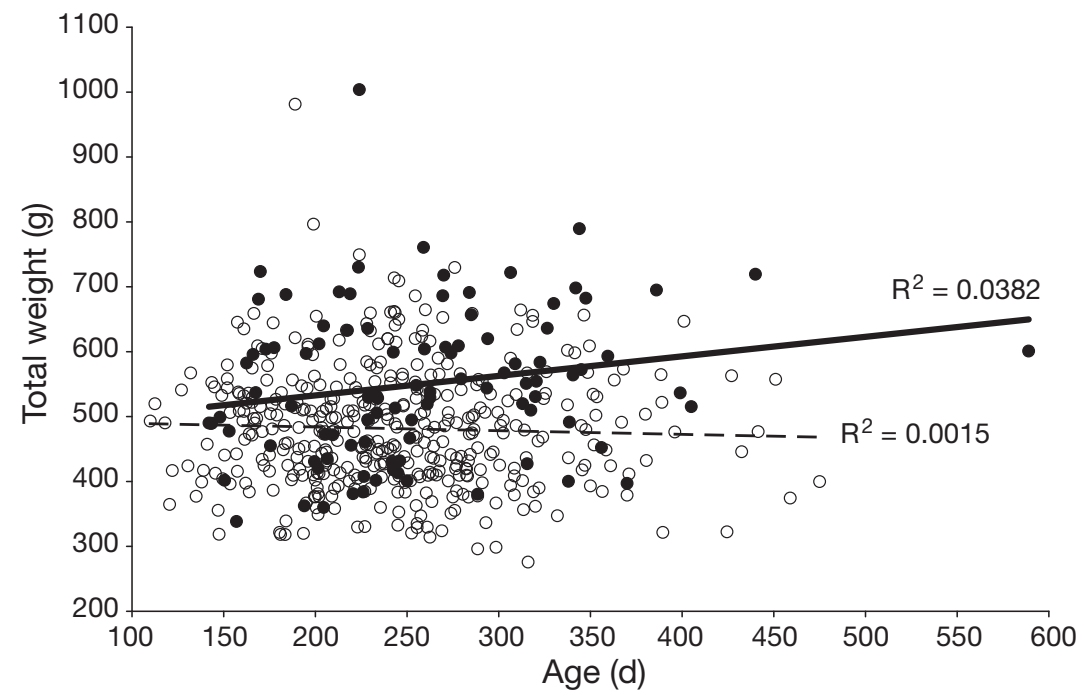

Fig. 5. Octopus pallidus. Total weight versus age for males $(\bullet)$ and females (०)

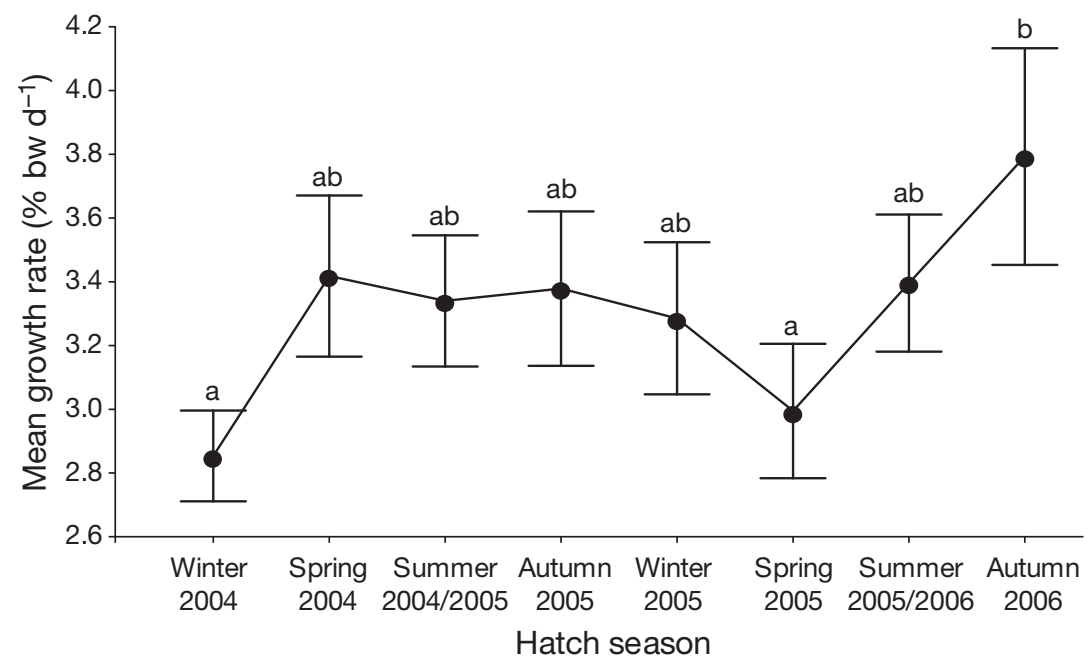

Fig. 6. Octopus pallidus. Mean instantaneous growth rate $\left(\% \mathrm{bw} \mathrm{d} \mathrm{d}^{-1}\right)$ by hatch season, with significant differences in mean growth denoted by different letters $(\mathrm{a}, \mathrm{b})$ as determined by a Tukey's B post hoc test. bw = body weight
TW $=560 \mathrm{~g}$ and $452 \mathrm{~g}$ for Wi 2004 and $\mathrm{Au} 2006$, respectively), with the males being consistently larger than the females until the autumn 2006 hatch season (Fig 8b).

\section{DISCUSSION}

This study has determined that stylet increment analysis is a feasible method of octopus age and growth estimation that does not rely on unfounded assumptions such as the age/size relationship recommended for MPA, but allows for and detects individual growth heterogeneity. Stylet increment analysis has provided a more detailed and accurate depiction of individualbased octopus age and growth than has previously been achievable. This has been accomplished by calculating growth for the life span of the individual, as opposed to dependence on the size classes obtained and time at liberty restraints evident in MPA and tag-recapture studies, respectively. Hence, stylet increment analysis is a promising prospect for application to other species and their fisheries, e.g. Octopus vulgaris.

Daily growth increments in Octopus pallidus were only validated to $245 \mathrm{~d}$ (Doubleday et al. 2006). This issue was overcome by a single reader observing over 5000 stylet images from octopus aged from 110 to $589 \mathrm{~d}$ and finding no anomalies in increment formation between octopus of different ages. As a result, the maximum age for $O$. pallidus summer haul season in 2005/06, octopus mostly hatched during the autumn and/or winter of the preceding year $(2005 / 06=40 \%$ [Au], $43 \%$ [Wi]) (Fig. 7) The haul seasons with the highest overall growth were summer 2005/06 for males and winter 2005 and 2006 for females.

When individuals were grouped according to hatch season mean growth generally correlated with temperature, with the exception of males hatched during summer 2005/06, which had lower mean growth rates than expected $\left(3.14 \% \mathrm{bw} \mathrm{d}^{-1}\right)$ for the higher temperatures $\left(17.3^{\circ} \mathrm{C}\right)$ (Fig. 8a). Mean weight declined progressively from hatch season to hatch season for both males (mean total weight [TW] $=658 \mathrm{~g}$ and $443 \mathrm{~g}$ for Wi 2004 and Au 2006, respectively) and females (mean has now been estimated as $589 \mathrm{~d}$ for males and $475 \mathrm{~d}$ for females, with $8.2 \%$ of males and $6.3 \%$ of females older than $350 \mathrm{~d}$, suggesting a typical life span of approximately 12 mo after hatching. Males were significantly larger and older on average than females. Similar observations have been made in other octopus species, where females decrease in weight due to egg laying and not feeding while brooding (O'Dor \& Wells 1978), and die shortly after the eggs hatch (Ambrose 1988). Weight at age did not show any specific relationships with gender or haul season, nor was there any relationship evident between age and size, in either total weight, mantle length or stylet morphology, for either sex. This lack of any age-size relationship indicates high levels of growth plasticity. 


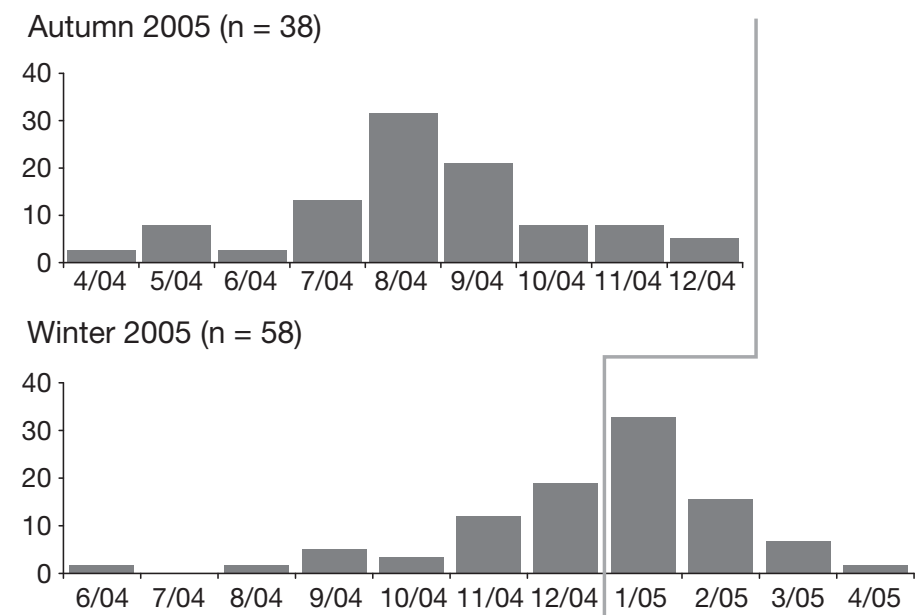

$$
\text { Spring } 2005(n=46)
$$
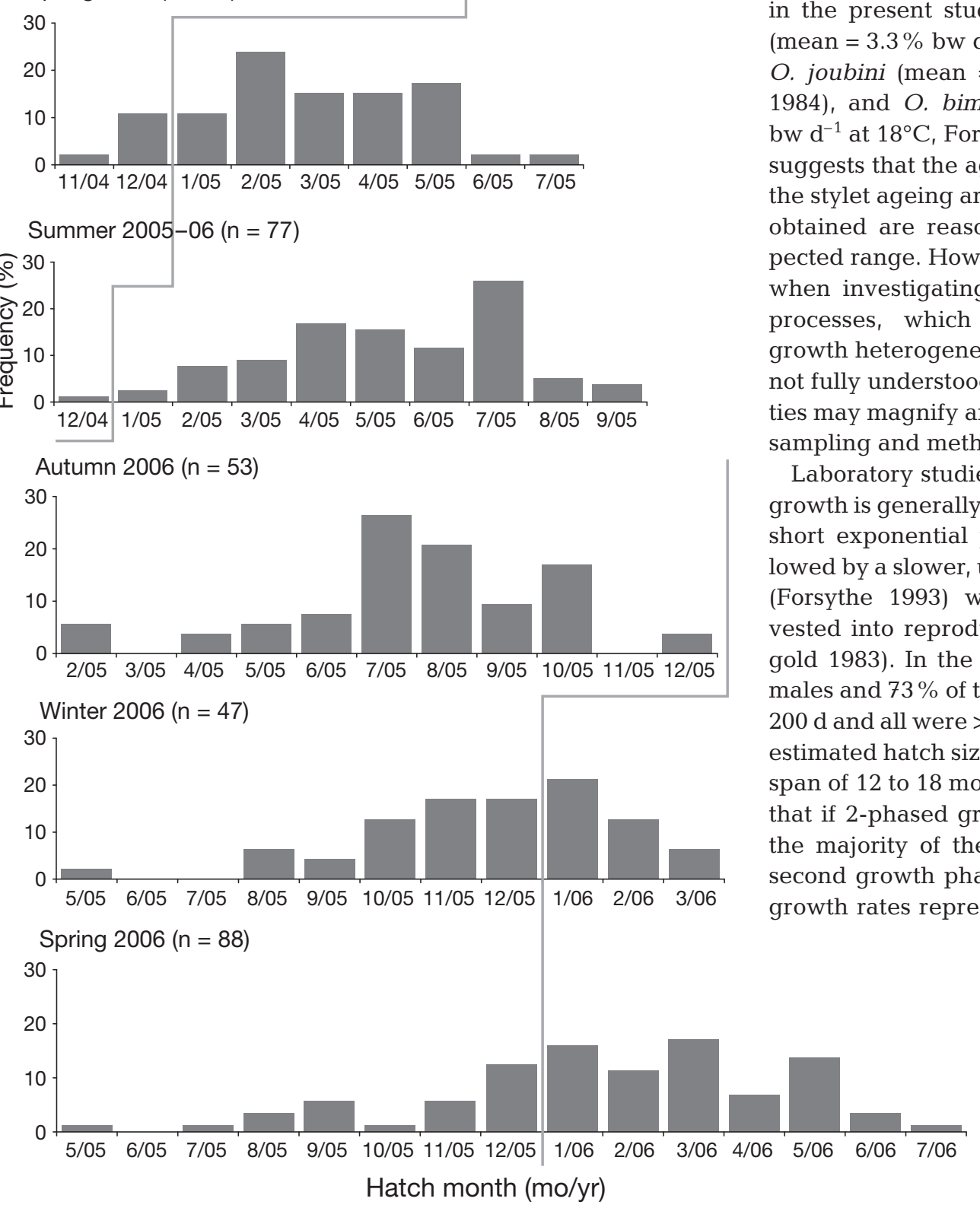

Growth plasticity is well documented for cephalopods (Mangold \& von Boletzky 1973, Boyle \& von Boletzky 1996, Moltschaniwskyj 2004), with variables such as temperature (Forsythe \& Van Heukelem 1987) and diet (García García \& Aguado Giménez 2002) having very strong influences on growth. In the present study the fastest growing individuals grew 5 times the rate of the slowest (1.32 to $6.9 \% \mathrm{bw} \mathrm{d}^{-1}$ ), indicating that individual growth heterogeneity overshadowed any influence of gender specific growth, even though there were significant differences in mean weight and age between males and females. Species in which laboratory studies have demonstrated similar growth rates to those in the present study include: Octopus maya $\left(\right.$ mean $=3.3 \%$ bw d $^{-1}$, Domingues et al. 2007), O. joubini (mean $=4.62 \% \mathrm{bw} \mathrm{d}^{-1}$, Forsythe 1984), and $O$. bimaculoides (mean $=3.56 \%$ bw d $\mathrm{d}^{-1}$ at $18^{\circ} \mathrm{C}$, Forsythe \& Hanlon 1988). This suggests that the age estimates obtained from the stylet ageing are valid, as the growth rates obtained are reasonable and within the expected range. However, it must be considered when investigating octopus growth that the processes, which cause strong individual growth heterogeneity in cephalopods, are still not fully understood and that these uncertainties may magnify any discrepancies caused by sampling and method analysis bias.

Laboratory studies suggest that cephalopod growth is generally 2-phased, and consists of a short exponential phase of high growth followed by a slower, usually power growth stage (Forsythe 1993) where more energy is invested into reproductive development (Mangold 1983). In the present study, $77 \%$ of the males and $73 \%$ of the females were older than $200 \mathrm{~d}$ and all were $>245 \mathrm{~g}$ in total weight. At an estimated hatch size of $0.25 \mathrm{~g}$ and a typical life span of 12 to $18 \mathrm{mo}$, it is reasonable to assume that if 2-phased growth exists in nature then the majority of these octopuses were in the second growth phase at time of capture. The growth rates represented here are, therefore,
Fig. 7. Octopus pallidus. Percent frequency of female octopus for each hatch month separated by haul season 

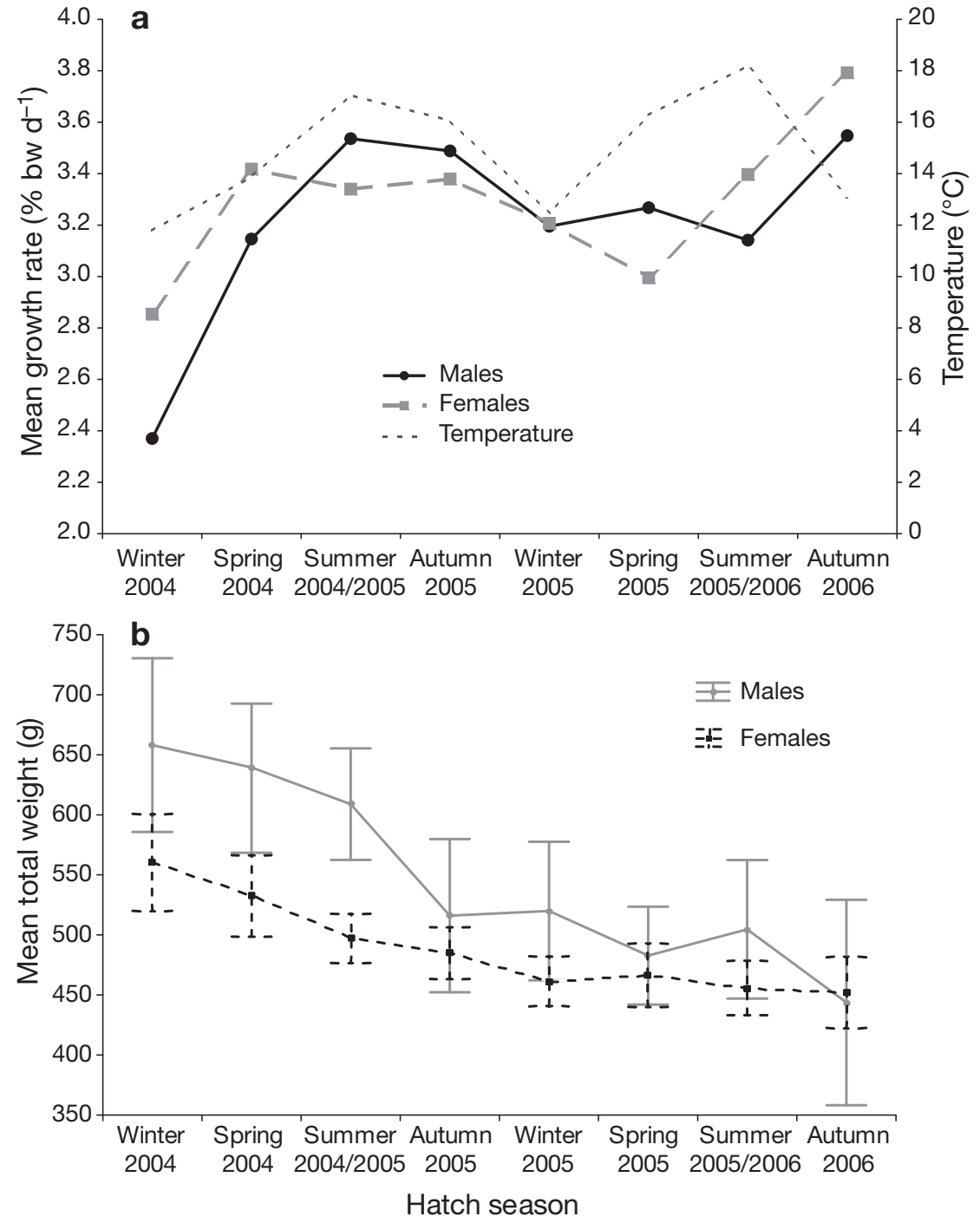

Fig. 8. Octopus pallidus. (a) Octopus mean instantaneous growth rate ( $\% \mathrm{bw} \mathrm{d}^{-1}$ ) and water temperature and (b) octopus mean total weight, grouped into hatch seasons

composites of the 2 phases. Attempts were made to capture a range of octopus sizes and developmental stages using variable pot volumes; however, this failed to occur potentially due to the selectivity of the fishing method and/or location of the research line.

A potential extension to this study is to investigate whether Octopus pallidus displays 2-phased growth in the wild. This could be achieved by capturing juveniles from a range of ages up to $150 \mathrm{~d}$ using a method such as scallop dredging, which is known to collect juvenile $O$. pallidus (Semmens et al. 2000). By combining the acquired data with the present study a composite picture of $O$. pallidus growth throughout the entire life span in relation to seasonal variability could be achieved.

A single sampling location was used to minimise the influence of spatial variability and potential mixing of populations. Females dominated catches, averaging more than $80 \%$ for each sampling trip. The typical composition in the commercial fishery is $45 \%$ males and $55 \%$ females (authors' unpubl. data), signifying that the research line sex ratio does not truly represent the population. Possible explanations for this skewed gender profile are spatial partitioning of genders by depth and/or habitat, as observed in Octopus vulgaris (Smale \& Buchan 1981), or the longer soak times for the research line (approximately 3 times longer than in the commercial fishery), leading to higher proportions of females because males are more transient as they do not need to care for egg batches. This was also observed in O. vulgaris (O'Dor \& Wells 1978).

Calculated over the life span of the individual, female growth was significantly influenced by hatch season. This was not evident for males, possibly due to the smaller sample sizes. Females caught during the winter 2005 and 2006 haul seasons, the majority of which were hatched during the late spring and/or summer and were juveniles during the summer or autumn of the preceding year, had the highest mean growth rates. Seasonally higher temperatures at hatching and during early development, which resulted in faster overall growth suggests that the Forsythe effect, where octopuses that hatch during increasing temperatures will grow faster and ultimately larger than individuals hatched only weeks previously at slightly lower temperatures (Forsythe 2004), could be a contributing factor to growth plasticity on a seasonal basis. However, higher growth rates did not translate into ultimately larger octopuses. As sampling progressed the mean size and age of the octopuses decreased while growth rates generally increased with seasonal fluctuations. These trends indicate size selective fishing mortality was occurring, where the continual fishing, or fishing down, of the research line led to larger, more dominant individuals being replaced with smaller, younger and quicker growing octopuses. Fishing down of the research line was intentional and instigated to test for the effects of continual fishing pressure on a localised area.

Daily periodicity of stylet increment formation appears to be an endogenous process, for daily temperatures at $25 \mathrm{~m}$ in Bass Strait waters are relatively consistent (Sandery \& Kämpf 2007). Octopus pallidus is 
not known to perform daily vertical migrations and sunlight at these depths and within pots is minimal. The stylets of captive O. pallidus also showed no influence of temperature or light patterns on the daily periodicity of increment formation and had extremely similar microstructures to those of the wild individuals (Doubleday et al. 2006). This is an important consideration for it allows stylet increments to be examined with the knowledge that their formation has not been confounded by environmental variables. When the combined low discard rates of $13.7 \%$ for males and $19.5 \%$ for females are compared with that for beak microstructure increment analysis of up to $81 \%$ in $O$. vulgaris (Oosthuizen 2003), stylet increment analysis proves to be an effective method of age estimation. Low discard rates were attributed to each octopus having $4(2 \times$ per stylet $)$ potential sections, providing a buffer for unsuccessful stylet preparation attempts. However, potential refinements to stylet preparation and age estimation may include investigating mounting mediums with lower melting points to minimise heat stress, machine polishing to increase production and accuracy, and using computer programs that estimate increment numbers.

This study is the first of its kind to give a detailed account of the age and growth of a wild octopus population using stylet increment analysis, revealing that Octopus pallidus has a maximum age of approximately $1.6 \mathrm{yr}$, that gender and hatch season derived differences in growth are secondary to individual growth heterogeneity and that age has no relationship with size for adults. These findings support the increasing emphasis on the importance of growth plasticity in octopus biology (Moltschaniwskyj 2004). The next step is to apply this method to other octopus species, following appropriate species-specific validation experiments, particularly for those with alternative life histories (i.e. planktonic hatchlings) and potentially different growth patterns. Stylet increment analysis is a promising technique that may fulfill a role similar to statoliths and otoliths assisting in taking octopus growth studies out of the laboratory, away from assumptions that were unavoidable in the past, and into the wild.

Acknowledgements. We thank Z. A. Doubleday, Tasmanian Aquaculture and Fisheries Institute, for assisting in sample collection and demonstrating the ageing techniques, and J. Mansbridge, CSIRO, for providing temperature data. We also thank the Hardy family, the captains and crews of the 'William L' and the 'Seafarer', and all the workers at T.O.P Fish Pty Ltd who assisted in sample collection. This study was supported with funding from the Department of Primary Industries and Water, approved by the Animal Ethics Committee of the University of Tasmania under project no. A0008130.

\section{LITERATURE CITED}

Ambrose RF (1988) Population dynamics of Octopus bimaculatus: influence of life history patterns, synchronous reproduction and recruitment. Malacologia 29:23-39

Bettencourt V, Guerra A (2001) Age studies based on daily growth increments in statoliths and growth lamellae in cuttlebone of cultured Sepia officinalis. Mar Biol 139: 327-334

Bizikov VA (2004) The shell in Vampyropoda (Cephalopoda): morphology, functional role and evolution. Ruthenica (Suppl) 3:1-88

Boyle PR, von Boletzky S (1996) Cephalopod populations: definitions and dynamics. Philos Trans R Soc Lond B Biol Sci 351:985-1002

Boyle PR, Rodhouse PG (2005) Cephalopods. Blackwell Science, Oxford

Campana SE (2001) Accuracy, precision and quality control in age determination, including a review of the use and abuse of age validation methods. J Fish Biol 59:197-242

Challier L, Royer J, Robin JP (2002) Variability in age-atrecruitment and early growth in English Channel Sepia officinalis described with statolith analysis. Aquat Living Resour 15:303-311

> Cortez T, Gonzalez AF, Guerra A (1999) Growth of Octopus mimus (Cephalopoda, Octopodidae) in wild populations. Fish Res 42:31-39

> Domain F, Jouffre D, Caverivière A (2000) Growth of Octopus vulgaris from tagging in Senegalese waters. J Mar Biol Assoc UK 80:699-705

Domingues PM, López N, Muñoz JA, Maldonado T, Gaxiola G (2007) Effects of a dry pelleted diet on growth and survival of the Yucatan octopus, Octopus maya. Aquac Nutr 13:273-280

Doubleday Z, Semmens JM, Pecl GT, Jackson G (2006) Assessing the validity of stylets as ageing tools in Octopus pallidus. J Exp Mar Biol Ecol 338:35-42

FAO (2005) Global production statistics 1950-2005. UN Food Agric Org. Available at: www.fao.org. Accessed Aug 2007

Forsythe JW (1984) Octopus joubini (Mollusca: Cephalopoda): a detailed study of growth through the full life cycle in a closed seawater system. J Zool 202:393-417

Forsythe JW (1993) A working hypothesis of how seasonal temperature change may impact the field growth of young cephalopods. In: Okutani T, O'Dor RK, Kubodera T (eds) Recent advances in cephalopod fisheries biology. Tokai University Press, Tokyo

Forsythe JW (2004) Accounting for the effects of temperature on squid growth in nature: from hypothesis to practice. Mar Freshw Res 55:331-339

Forsythe JW, Hanlon RT (1988) Effect of temperature on laboratory growth, reproduction and life span of Octopus bimaculoides. Mar Biol 98:369-379

Forsythe JW, Van Heukelem WF (1987) Growth. In: Boyle PR (ed) Cephalopod life cycles, 2. Academic Press, London

> García García B, Aguado Giménez F (2002) Influence of diet on ongrowing and nutrient utilization in the common octopus (Octopus vulgaris). Aquaculture 211:171-182

Hernández-López JL, Castro-Hernández JJ (2001) Age determination from the daily deposition of concentric rings on common octopus (Octopus vulgaris) beaks. Fish Bull 99: $679-684$

Iglesias J, Otero JJ, Moxica C, Fuentes L, Sánchez FJ (2004) The completed life cycle of the octopus (Octopus vulgaris, Cuvier) under culture conditions: paralarval rearing using Artemia and zoeae, and first data on juvenile growth up to 8 months of age. Aquac Int 12:481-487 
Iribarne OO (1990) Use of shelter by the small Patagonian octopus Octopus tehuelchus: availability, selection and effects on fecundity. Mar Ecol Prog Ser 66:251-258

Jackson GD (1994) Application and future potential of statolith increment analysis in squids and sepioids. Can J Fish Aquat Sci 51:2612-2625

> Jackson GD, Forsythe JW, Hixon RF, Hanlon RT (1997) Age, growth, and maturation of Lolliguncula brevis (Cephalopoda: Loliginidae) in the northwestern Gulf of Mexico with a comparison of length-frequency versus statolith age analysis. Can J Fish Aquat Sci 54:2907-2919

Jackson GD, Alford RA, Choat JH (2000) Can length frequency analysis be used to determine squid growth? An assessment of ELEFAN. ICES J Mar Sci 57:948-954

Joll LM (1977) Growth and food intake of Octopus tetricus (Mollusca: Cephalopoda) in aquaria. Aust J Mar Freshw Res 28:45-56

Katsanevakis S, Verriopoulos G (2004) Den ecology of Octopus vulgaris Cuvier, 1797, on soft sediment: availability and types of shelter. Sci Mar 68:147-157

Leporati SC, Pecl GT, Semmens JM (2007) Cephalopod hatchling growth: the effects of initial size and seasonal temperatures. Mar Biol 151:1375-1383

Lombarte A, Rufino MM, Sánches P (2006) Statolith identification of Mediterranean Octopodidae, Sepiidae, Loliginidae, Ommastrephidae and Enoploteuthidae based on warp analyses. J Mar Biol Assoc UK 86:767-771

Mangold K, von Boletzky S (1973) New data on reproductive biology and growth in Octopus vulgaris. Mar Biol 19:7-12

Mangold K (1983) Food, feeding and growth in cephalopods. Mem Mus Vic 44:81-93

Miliou H, Fintikaki M, Kountouris T, Verriopoulos G (2005) Combined effects of temperature and body weight on growth and protein utilization of the common octopus, Octopus vulgaris. Aquaculture 249:245-256

Moltschaniwskyj N (2004) Understanding the process of growth in cephalopods. Mar Freshw Res 55:379-386

O'Dor RK, Wells MJ (1978) Reproduction versus somatic growth: hormonal control in Octopus vulgaris. J Exp Biol

Editorial responsibility: Hans Heinrich Janssen, Oldendorf/Luhe, Germany
$77: 15-31$

Oosthuizen A (2003) A development and management framework for a new Octopus vulgaris fishery in South Africa. $\mathrm{PhD}$ thesis, Rhodes University, Grahamstown

Pecl GT, Moltschaniwskyj NA (1999) Somatic growth processes: How are they altered in captivity? Proc R Soc Lond B Biol Sci 266:1133-1139

Raya CP, Hernández-García CL (1998) Growth lines within the beak microstructure of the octopus Octopus vulgaris Cuvier, 1797. S Afr J Mar Sci 20:135-142

Sandery PA, Kämpf J (2007) Transport timescales for identifying seasonal variation in Bass Strait, south-eastern Australia. Estuar Coast Shelf Sci 74:684-696

Segawa S, Nomoto A (2002) Laboratory growth, feeding, oxygen consumption and ammonia excretion of Octopus ocellatus. Bull Mar Sci 7:801-813

Semmens JM, Haddon M, Lyle JM (2000) Bass Strait central zone scallop survey, June 2000, AFMA final report. Tasmanian Aquac Fish Inst, Hobart

> Semmens JM, Pecl G, Villanueva R, Jouffre D, Sobrino I, Wood JW, Rigby P (2004) Understanding octopus growth: patterns, variability and physiology. Mar Freshw Res 55: 367-377

Semmens JM, Pecl GT, Gillanders BM, Waluda CM and others (2007) Approaches to resolving cephalopod movement and migration patterns. Rev Fish Biol Fish 17:401-423

> Smale MJ, Buchan PR (1981) Biology of Octopus vulgaris off the east coast of South Africa. Mar Biol 65:1-12

Sobrino I, Real M (2003) First approach to the quantification of age pigment lipofuscin in brains from Octopus vulgaris (Mollusca: Cephalopoda). In: Biology, recruitment, and culture. Cephalopod International Advisory Council (CIAC) Symposium, Aberdeen (Abstract)

Stranks TN (1988) Rediscription of Octopus pallidus (Cehpahlopoda: Octopodidae) from south-eastern Australia. Malacologia 29:275-287

Ziegler PE, Lyle JM, Pecl GT, Moltschaniwskyj NA, Haddon M (2007) Tasmanian scalefish fishery 2006. Tasmanian Aquac Fish Inst, Hobart

Submitted: September 27, 2007; Accepted: April 29, 2008

Proofs received from author(s): August 29, 2008 